Int. J. Electrochem. Sci., 12 (2017) $3709-3720$

\title{
Novel Strategy for Electroanalytical Detection of Antipsychotic Drugs Chlorpromazine and Thioridazine; Possibilities for Simultaneous Determination
}

\author{
B. B. Petkovic ${ }^{1, *}$, D. Kuzmanović ${ }^{2}$, T. Dimitrijevic ${ }^{2}$, M. P. Krstić ${ }^{3}$, D. M. Stanković, ${ }^{4,5}$ \\ ${ }^{1}$ Department of Chemistry, Faculty of Natural Sciences and Mathematics, University of Priština, Lole \\ Ribara 29, 38220 Kosovska Mitrovica, Serbia) \\ ${ }^{2}$ Faculty of Chemistry, University of Belgrade, Studentski trg 12-16, 11000 Belgrade, Serbia \\ ${ }^{3}$ Faculty of Veterinary Medicine, University of Belgrade, Bulevar oslobođenja 18, 11000 Belgrade, \\ Serbia \\ ${ }^{4}$ Innovation center of the Faculty of Chemistry, University of Belgrade, POB 51, 118, 11158 Belgrade, \\ Serbia \\ ${ }^{5}$ The Vinča Institute of Nuclear Sciences, University of Belgrade, POB 522, 11001 Belgrade, Serbia \\ *E-mail: bedpet@orion.rs, branka.petkovic@pr.ac.rs
}

doi: $10.20964 / 2017.05 .34$

Received: 13 February 2017 / Accepted: 8 March 2017 / Published: 12 April 2017

\begin{abstract}
A simple and fast method for determination of two phenothiazine drugs, chlorpromazine (CPZ) and thioridazine (TDZ), at the boron-doped diamond electrode (BDDE) was proposed. Oxidation peaks on potentials higher than $1 \mathrm{~V}$ were used for quantitation of investigated phenothiazines due to better selectivity over common interfering compounds in urine. Differential pulse voltammetry was applied for trace determination of CPZ and TDZ, in Britton-Robinson buffer solution at optimal $\mathrm{pH}$. Under optimized DPV conditions a linear analytical curve was obtained from $1.0 \times 10^{-7}$ to $4.0 \times 10^{-5} \mathrm{M}$ with a detection limit of $0.3 \times 10^{-7} \mathrm{M}$ (for CPZ) and in the concentration range of $2 \times 10^{-7} \mathrm{M}$ to $4.0 \times 10^{-5} \mathrm{M}$, with a detection limit of $1.2 \times 10^{-7} \mathrm{M}$ (for TDZ). The applicability of the method was proved by determination of CPZ and TDZ by proposed procedures in spiked urine samples. The electrochemical behavior of those two important tranquilizers in different solvents was described, exploring the possibility of simultaneous determination.
\end{abstract}

Keywords: voltammetric method, chlorpromazine, thioridazine, boron-doped diamond electrode, human urine

$\underline{\text { FULL TEXT }}$ 
(C) 2017 The Authors. Published by ESG (www.electrochemsci.org). This article is an open access article distributed under the terms and conditions of the Creative Commons Attribution license (http://creativecommons.org/licenses/by/4.0/). 